\title{
Incorporation of Cytochrome Oxidase into Cardiolipin Bilayers and Induction of Nonlamellar Phases ${ }^{\dagger}$
}

\author{
Gary L. Powell, $\$ \S$ Peter F. Knowles," and Derek Marsh ${ }^{*, \downarrow}$ \\ Max-Planck-Institut für biophysikalische Chemie, Abteilung Spektroskopie, D-3400 Göttingen, Federal Republic of Germany, \\ and Astbury Department of Biophysics, University of Leeds, Leeds LS2 9JT, U.K. \\ Received October 16, 1989; Revised Manuscript Received February 6, 1990
}

\begin{abstract}
Cytochrome oxidase from beef heart has been lipid-substituted with beef heart cardiolipin. The lipid phase behavior and protein aggregation state of the reconstituted complexes have been studied with ${ }^{31}$ P NMR, freeze-fracture electron microscopy, and saturation-transfer ESR of the spin-labeled protein. In the absence of salt, the lipid has a lamellar arrangement, and the protein is integrated and uniformly distributed in the membrane vesicles and undergoes rapid rotational diffusion. The presence of the protein stabilizes the cardiolipin lamellar phase against salt-induced transitions to the inverted hexagonal phase. The threshold salt concentration becomes higher and the extent of conversion becomes lower with decreasing lipid:protein ratio. In high salt, lamellar-phase lipid with integrated protein coexists with hexagonal-phase lipid free of protein, and the rotational diffusion of the protein is drastically reduced as a result of the high packing density.
\end{abstract}

$\mathrm{C}_{\mathrm{y}}$ ytochrome $c$ oxidase is an integral protein and constitutes the terminal member of the respiratory chain in the inner mitochondrial membrane. The principal lipid components of this membrane are phosphatidylcholine, phosphatidylethanolamine, and cardiolipin. Previously, the endogenous lipid of the enzyme has been replaced by dimyristoylphosphatidylcholine to form reconstituted complexes which have been used for the study of lipid/protein interactions (Knowles et al., 1979, 1981; Powell et al., 1985, 1987). In these experiments, a strong selectivity of cytochrome oxidase for spin-labeled cardiolipin compared with spin-labeled phosphatidylcholine and phosphatidylethanolamine was indicated. Cardiolipin has been found to be particularly effective in restoring the activity of delipidated cytochrome oxidase ( $\mathrm{Yu}$ et al., 1975; Robinson et al., 1980) and is also capable of enhancing the enzymatic activity of cytochrome oxidase reconstituted with dimyristoylphosphatidylcholine (Abramovitch et al., 1990; Marsh \& Powell, 1988).

Cardiolipin from beef heart mitochondria contains approximately $90 \%$ linoleate chains (Powell et al., 1985), and transitions from the lamellar bilayer phase to the inverted hexagonal phase can be induced by mono- and divalent ions, as well as by $\mathrm{pH}$ titration (Rand \& Sengupta, 1972; Seddon et al., 1983). The modulation of the ion-induced polymorphic phase behavior has been shown to depend sensitively on the detailed chain and headgroup structure of the cardiolipin molecule (Powell \& Marsh, 1985). In several instances, integral proteins tend to stabilize the lipid lamellar phase relative to nonlamellar phases [see, e.g., De Grip et al. (1979) and Taraschi et al. $(1982,1983)]$. However, a Ca ${ }^{2+}$-induced inverted hexagonal phase has been observed for cytochrome oxidase which was supplemented with cardiolipin (Rietveld et al., 1987). This allows one to explore the effects of non-

\footnotetext{
'This work was supported in part by the U.S. Public Health Service (Grant HL 38190) and by the National Science Foundation (USA-FRG Cooperative Science Programme Grant INT 8521597).

'Max-Planck-Institut für biophysikalische Chemie.

'Permanent address: Department of Biological Sciences, Clemson University, Clemson, SC 29634-1903.

"University of Leeds.
}

lamellar phase formation on the protein incorporation and distribution.

In the present experiments, we have substituted the endogenous lipid of cytochrome oxidase by cardiolipin and characterized the reconstituted protein/lipid complexes by ${ }^{31} \mathrm{P}$ nuclear magnetic resonance (NMR), ${ }^{1}$ freeze-fracture electron microscopy, and protein rotational diffusion measurements. Special attention has been devoted to the effects of the protein on the salt-induced transition to the inverted hexagonal phase. The effects of nonlamellar phase transitions on protein distribution could be important for protein crystallization and for liposome technology.

\section{Materials and Methods}

Beef heart cardiolipin (sodium salt) and cytochrome $c$ (grade VI) were obtained from Sigma Chemical Co. (St. Louis, MO). Dimyristoylphosphatidylcholine puriss was from Fluka (Buchs, Switzerland). Spin-labeled maleimide (4-maleimido-2,2,6,6tetramethyl-1-piperidineoxyl) was from Syva (Palo Alto, CA).

Cytochrome oxidase was prepared from beef heart by using the method of $\mathrm{Yu}$ et al. (1975) with modifications given in Cable and Powell (1980). Lipid substitution by dimyristoylphosphatidylcholine was carried out according to the method described by Knowles et al. (1979), but with omission of sucrose and $\mathrm{KCl}$ from the buffers. Further details are given in Powell et al. (1987). Lipid substitution by cardiolipin was performed by a similar method, except that two exchanges with a 10-fold excess of cardiolipin were employed. Cardiolipin samples were handled under $\mathrm{N}_{2}$ to inhibit lipid peroxidation. The final cardiolipin-substituted preparations were centrifuged through either 1,2 , or $4 \mathrm{M} \mathrm{NaCl}$ to resolve the protein/lipid complexes from unincorporated lipid. Sucrose density gradient centrifugation then demonstrated that the complexes sedimented as a single band and contained no free lipid. Salt concentration was varied by resuspending and washing the

\footnotetext{
${ }^{1}$ Abbreviations: NMR, nuclear magnetic resonance; ESR, electron spin resonance; STESR, saturation-transfer ESR; $V_{2}$, second harmonic ESR absorption signal detected $90^{\circ}$ out-of-phase with respect to the field modulation; EM, electron microscopy; TLC, thin-layer chromatography; $\mathrm{L}_{\alpha}$, fluid lamellar lipid phase; $\mathrm{H}_{\mathrm{II}}$, inverted hexagonal lipid phase.
} 
reconstituted samples in buffers of the required $\mathrm{NaCl}$ concentration. Reversibility of the salt-induced changes in the ${ }^{31}$ P NMR spectra was established with those complexes which were originally prepared in high salt. The buffers used throughout were $10 \mathrm{mM}$ Tris (or Hepes) $/ 1 \mathrm{mM}$ EDTA, pH 7.4 .

Lipid phosphorus was assayed by the method of Eibl and Lands (1969) and protein according to Lowry et al. (1951). Lipid:protein ratios are quoted on the basis of moles of lipid phosphate per mole of enzyme, using a molecular weight of $200 \mathrm{~K}$ for cytochrome oxidase.

To assess the degree of lipid substitution, the lipid was extracted from the cardiolipin-substituted complex by using the technique of Bligh and Dyer (1959) and analyzed by two-dimensional thin-layer chromatography. The first TLC dimension was run with $\mathrm{CHCl}_{3} / \mathrm{CH}_{3} \mathrm{OH} / 6 \mathrm{~N} \mathrm{NH} \mathrm{NH}_{4} \mathrm{OH}$ $(65: 35: 5 \mathrm{v} / \mathrm{v})$ and the second dimension with $\left(\mathrm{CH}_{3}\right)_{2} \mathrm{CO} /$ $\mathrm{CHCl}_{3} / \mathrm{CH}_{3} \mathrm{OH} / \mathrm{CH}_{3} \mathrm{COOH} / \mathrm{H}_{2} \mathrm{O}(40: 30: 10: 10: 5 \mathrm{v} / \mathrm{v})$. No phospholipids other than cardiolipin and a trace of monolysocardiolipin were detected in the extracted lipid, on developing the TLC plates with molybdate spray.

Covalent spin-labeling of the enzyme with the nitroxide derivative of maleimide was carried out either in cholate or in dodecyl maltoside, prior to lipid substitution and reconstitution, essentially according to the method described by Dasgupta and Wharton (1977). The spin-labeled enzyme was resolved from unreacted label by chromatography on Sephadex G-25.

Proton dipolar decoupled 109- $\mathrm{MHz}{ }^{31} \mathrm{P}$ NMR spectra were recorded on a Bruker WH-270 spectrometer. The direct free induction decay was collected with an $11-\mu \mathrm{s} 90^{\circ}$ pulse length and phase cycling. The proton decoupling power was approximately $20 \mathrm{~W}$, and the duty cycle of the gated decoupling was $0.2 \%$. The samples were thermostated at $20^{\circ} \mathrm{C}$. Chemical shift anisotropies were measured as the distance between the points of maximum slope in the outer edges of the powder pattern.

Saturation-transfer ESR spectra ( $\mathrm{V}_{2}^{\prime}$ display) were recorded on a Varian Century Line $9 . \mathrm{GHz}$ spectrometer, with a modulation frequency of $50 \mathrm{kHz}$ and phase quadrature detection at $100 \mathrm{kHz}$. Pelleted membrane samples ( $5 \mathrm{~mm}$ in length) were contained in $1-\mathrm{mm}$ i.d. glass capillaries accommodated in standard 4-mm quartz ESR tubes containing silicone oil for thermal buffering. The microwave power was set to give an average $\mathrm{H}_{1}$ microwave field over the sample of $0.25 \mathrm{G}$ (Fajer \& Marsh, 1982; Hemminga et al., 1984). Effective rotational correlation times, referred to isotropically tumbling spin-labeled hemoglobin, were evaluated from the calibrations given in Horvâth and Marsh (1988).

Samples for freeze-fracture electron microscopy were rapidly frozen from room temperature in a slurry of coexisting solid and liquid nitrogen. Freeze-fracture, etching, platinum shadowing, and coating with carbon were carried out with a Balzers BAF 400D freeze-etch apparatus. The replicas were floated off in distilled water, washed overnight in $40 \%$ sodium hypochlorite followed by four 20 -min rinses in distilled water, and then transferred onto 200-mesh copper grids. Replicas were examined with a Phillips EM-200 electron microscope operating at a voltage of $60 \mathrm{kV}$.

\section{RESUlTS}

The proton dipolar decoupled ${ }^{31} \mathrm{P}$ NMR spectra of a cytochrome oxidase/cardiolipin complex of lipid:protein ratio 205:1 $\mathrm{mol} / \mathrm{mol}$, suspended in increasing concentrations of salt, are given in Figure 1. In $1.5 \mathrm{M} \mathrm{NaCl}$, the spectral line shape has axial symmetry with a negative chemical shift anisotropy,

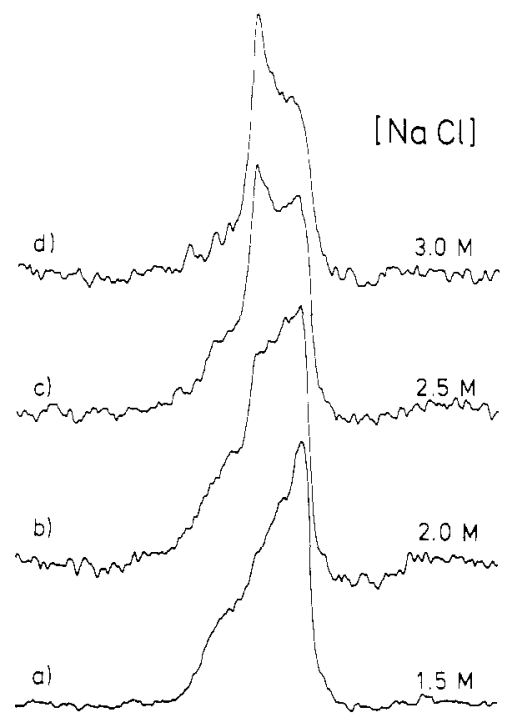

FIGURE 1: Proton dipolar decoupled 109-MHz ${ }^{31} \mathrm{P}$ NMR spectra of a cytochrome oxidase/cardiolipin complex of lipid:protein ratio 205:1 $\mathrm{mol} / \mathrm{mol}$, suspended in increasing concentrations of salt, at $20^{\circ} \mathrm{C}$ : (a) $1.5 \mathrm{M} \mathrm{NaCl}$; (b) $2.0 \mathrm{M} \mathrm{NaCl}$; (c) $2.5 \mathrm{M} \mathrm{NaCl}$; (d) $3.0 \mathrm{M} \mathrm{NaCl}$. Plot width $=16 \mathrm{kHz}(146 \mathrm{ppm})$.

characteristic of phospholipids in a lamellar arrangement [see, e.g., Seelig (1978)]. At this salt concentration, there are only very minor spectral components which do not correspond to a lamellar powder pattern. With increasing salt concentration, part of the spectral intensity is converted to a second component, the position of the peak of which can be correlated with the $\sigma_{\perp}$ region of a powder pattern of lipids in an inverted hexagonal arrangement [see, e.g., Cullis and De Kruijff (1979)]. This inverted hexagonal component has a chemical shift anisotropy of approximately half the size and the opposite sign to that from the lamellar component. For the lipid alone at high salt concentration, it has been demonstrated by X-ray diffraction that this characteristic ${ }^{31} \mathrm{P}$ NMR line shape corresponds to a lipid phase with hexagonal symmetry (Seddon et al., 1983; Powell \& Marsh, 1985). For this lipid:protein ratio, even at a salt concentration of $3 \mathrm{M} \mathrm{NaCl}$ (Figure 1d), some lamellar phase is still present (cf. below).

The ${ }^{31} \mathrm{P}$ NMR powder pattern line shapes for cytochrome oxidase/cardiolipin complexes of increasing lipid:protein ratio, in $4 \mathrm{M} \mathrm{NaCl}$, are given in Figure 2. The lipid alone gives rise to a spectrum characteristic solely of hexagonal-phase lipid, and with increasing protein content, an increasing proportion of the spectral intensity has the line shape characteristic of lipid in a lamellar phase. The ratio of the spectral line height in the region of the $\sigma_{\perp}$ peak for the hexagonal component to that in the region of the $\sigma_{\perp}$ peak for the lamellar component has been taken as an empirical indicator of the relative proportions of the two lipid phases. The dependence of this ratio on the salt concentration of the suspending medium is given for samples of different lipid:protein ratios in Figure 3. Because of spectral overlap, this ratio is not directly proportional to the relative proportions of the phases, but is nonetheless a reliable indicator of the qualitative trends. Increasing protein content in the complexes is seen to stabilize the lamellar phase against salt-induced transitions to the inverted hexagonal phase. The salt concentrations required for half-conversion to the $\mathrm{H}_{\mathrm{II}}$ phase are approximately in the following order: 1.5 $\mathrm{M} \mathrm{NaCl}$ for the lipid alone, $2.3 \mathrm{M} \mathrm{NaCl}$ for the complexes with lipid:protein ratio $370: 1$ and $205: 1 \mathrm{~mol} / \mathrm{mol}$, and $2.8 \mathrm{M}$ $\mathrm{NaCl}$ for the complex with lipid:protein ratio $110: 1 \mathrm{~mol} / \mathrm{mol}$. As was evident from Figure 2, the maximal extent of conversion to the inverted hexagonal phase decreases in the order 


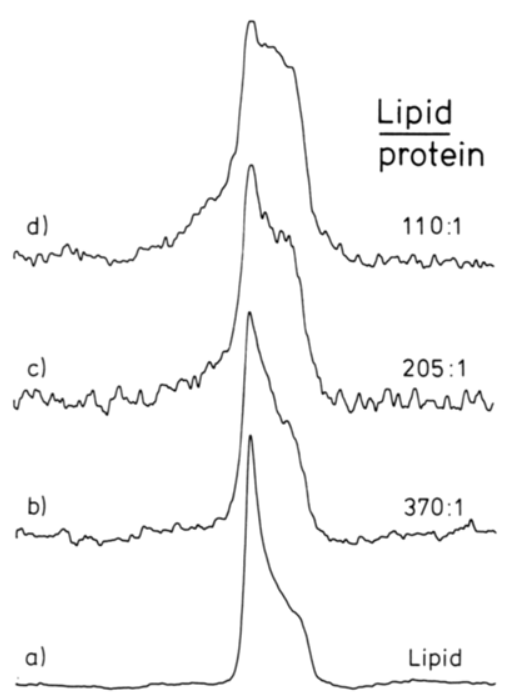

FIGURE 2: Proton dipolar decoupled 109- $\mathrm{MHz}^{31} \mathrm{P}$ NMR spectra of cytochrome oxidase/cardiolipin complexes of different lipid:protein ratios, dispersed in $4.0 \mathrm{M} \mathrm{NaCl}$, and recorded at $20^{\circ} \mathrm{C}$. (a) $\mathrm{Car}$ diolipin alone; (b) complex of lipid:protein ratio $=370: 1 \mathrm{~mol} / \mathrm{mol}$; (c) lipid:protein ratio $=205: 1 \mathrm{~mol} / \mathrm{mol}$; (d) lipid:protein ratio $=110: 1$ $\mathrm{mol} / \mathrm{mol}$. Plot width $=16 \mathrm{kHz}(146 \mathrm{ppm})$.

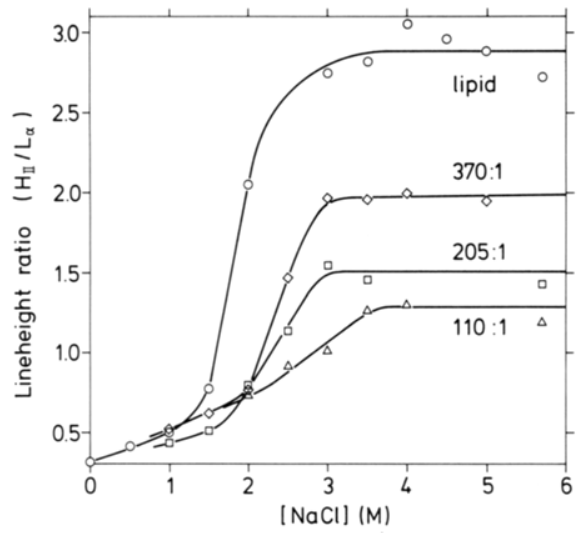

FIGURE 3: Ratio of the line heights $\left(\mathrm{H}_{\mathrm{II}} / \mathrm{L}_{\alpha}\right)$ in the $\sigma_{\perp}$ regions of the inverted hexagonal and lamellar components of the ${ }^{31} \mathrm{P}$ NMR spectra of cytochrome oxidase complexes of different lipid:protein ratios, as a function of salt concentration, $[\mathrm{NaCl}]$, of the suspending medium. Lipid:protein ratio $=110: 1 \mathrm{~mol} / \mathrm{mol}(\Delta) ; 205: 1 \mathrm{~mol} / \mathrm{mol}(\square) ; 370: 1$ $\mathrm{mol} / \mathrm{mol}(\diamond)$. Lipid alone (O). $T=20^{\circ} \mathrm{C}$.

of decreasing lipid:protein ratio. An attempt to separate the spectral components in Figure 2 reveals that approximately 70-90 bilayer lipids are stabilized per cytochrome oxidase at the different lipid:protein ratios.

The state of protein distribution in the cardiolipin matrix was investigated by freeze-fracture electron microscopy. Typical electron micrographs of a cytochrome oxidase/cardiolipin complex in the absence of salt and in the presence of $4 \mathrm{M} \mathrm{NaCl}$ are given in panels $\mathrm{A}$ and $\mathrm{B}$, respectively, of Figure 4. In the absence of salt, a relatively homogeneous distribution of protein-associated particles is observed in the plane of the membrane. The particle density is high because of the relatively low lipid:protein ratio of the sample, and this gives rise to a high proportion of cross-cleaved vesicles rather than fractures along the membrane interior. Only a relatively small proportion of the vesicles were free of intramembranous protein particles, in agreement with the results of sucrose density gradient centrifugation or the sedimentation of the complexes in high salt concentration. The intramembranous particles were not observed in preparations of lipid alone. In addition, the ${ }^{31} \mathrm{P}$ NMR results rule out the existence of lipidic particles sometimes found in $\mathrm{H}_{\mathrm{II}}$-forming lipids (Verkleij, 1984), since
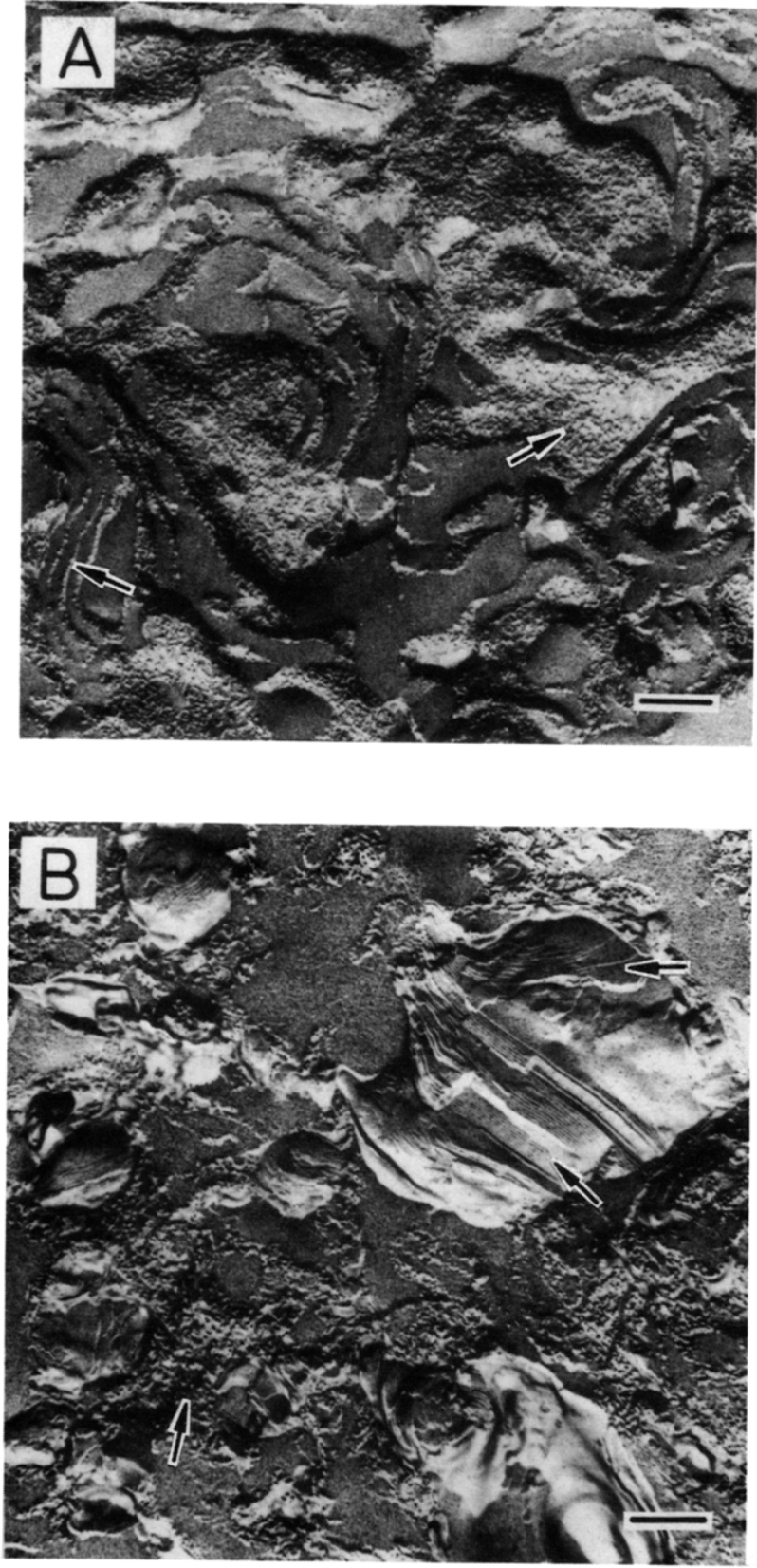

FIGURE 4: Freeze-fracture electron micrographs of cytochrome oxidase/cardiolipin complexes (lipid:protein ratio $120: 1 \mathrm{~mol} / \mathrm{mol}$ ), quenched from room temperature. (A) Suspended in $0 \mathrm{M} \mathrm{NaCl}$; from left to right, the arrows indicate cross-cleaved vesicle and particles distributed in the membrane plane; (B) suspended in $4 \mathrm{M} \mathrm{NaCl}$; from left to right, the arrows indicate particle-rich regions, $\mathrm{H}_{\mathrm{II}}$-phase lipid, and particle-free lipid regions. The bar represents $200 \mathrm{~nm}$ in each case. The shadowing direction is from the top of the micrograph downward in each case.

they would give rise to an isotropic spectral component and this is not detected.

In the presence of $4 \mathrm{M} \mathrm{NaCl}$, free lipid regions in coexistence with regions of high particle density were observed in the freeze-fracture electron micrographs (Figure 4B). The free lipid regions consisted predominantly of closely spaced tubes characteristic of inverted hexagonal-phase lipids [see, e.g., Verkleij (1984)]. The minimum spacing between these tubular features is approximately $75 \AA$, which corresponds reasonably well with the value of $70 \AA$ for the separation of the cylinders in the $\mathrm{H}_{\text {II }}$ phase of beef heart cardiolipin in 4 $\mathrm{M} \mathrm{NaCl}$, measured by X-ray diffraction (Seddon et al., 1983). The protein density is very high in the particle-containing regions, which leads to less clear fracturing patterns. Vesicle 


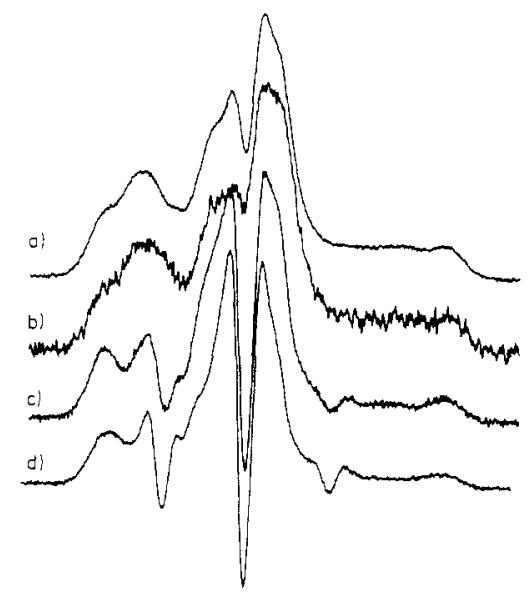

FIGURE 5: Second harmonic, $90^{\circ}$ out-of-phase saturation-transfer ESR spectra $\left(\mathrm{V}_{2}{ }^{\prime}\right.$ display) of maleimide spin-labeled cytochrome oxidase reconstituted in (a) dimyristoylphosphatidylcholine in the absence of salt at $2{ }^{\circ} \mathrm{C}$, (b) bovine cardiolipin in $4 \mathrm{M} \mathrm{NaCl}$ at $25^{\circ} \mathrm{C}$, (c) dimyristoylphosphatidylcholine in the absence of salt at $25^{\circ} \mathrm{C}$, and (d) bovine cardiolipin in the absence of salt at $25^{\circ} \mathrm{C}$. Total scan width $=100 \mathrm{G}$.

fracture faces can be seen and a large number of cross-cleaved vesicles. Figure $4 \mathrm{~B}$ was chosen to illustrate the structure of the free lipid regions, and underrepresents the overall population of protein-containing vesicles.

Attempts were made to fractionate the sample into its protein-rich and protein-poor parts by using sucrose density gradient centrifugation. These experiments were not successful, possibly because of the high salt concentrations simultaneously required to produce the protein segregation. Sedimentation of the complexes with high lipid:protein ratio $(1000: 1 \mathrm{~mol} / \mathrm{mol})$ in $3.5 \mathrm{M} \mathrm{NaCl}$, in which the pure lipid floats, produced a separation between a protein-rich fraction and a pure lipid component. At lower lipid:protein ratios, a clear separation was not obtained, suggesting that in most of the sample the protein segregation occurs with contiguous areas of protein-free lipid or that the protein-rich and protein-free regions are in some other way occluded. This conclusion was supported by lipid:protein ratio determinations on the protein-containing bands, which yielded values that were not much smaller than those of the starting material.

Saturation-transfer ESR experiments were carried out on the spin-labeled protein to gain information on the aggregation state of the cytochrome oxidase in complexes with cardiolipin. Saturation-transfer ESR spectra of cytochrome oxidase/cardiolipin complexes and dimyristoylphosphatidylcholine complexes are given in Figure 5. Complexes with cardiolipin in the presence and absence of salt (Figure $5 \mathrm{~b}, \mathrm{~d}$ ) are compared with complexes with dimyristoylphosphatidylcholine at temperatures below and above the gel-to-fluid-phase transition temperature (Figure $5 \mathrm{a}, \mathrm{c}$ ). In the absence of salt, the protein mobility in cardiolipin is similar to that in fluid-phase dimyristoylphosphatidylcholine, whereas in the presence of high salt it is more comparable to that in gel-phase lipid. This is clearly seen in the temperature dependences of the effective rotational correlation times, deduced from the low-field lineheight ratios, $L^{\prime \prime} / L$, of the STESR spectra of the various protein/lipid complexes, which are given in Figure 6. The effective rotational correlation times in the cardiolipin complexes do not exhibit the steep change observed at the gelto-fluid-phase transition (ca. $20^{\circ} \mathrm{C}$ ) for dimyristoylphosphatidylcholine. In the presence of $4 \mathrm{M} \mathrm{NaCl}$, the effective rotational correlation times for the cardiolipin complex remain of the same order as in the lipid gel phase, and in the

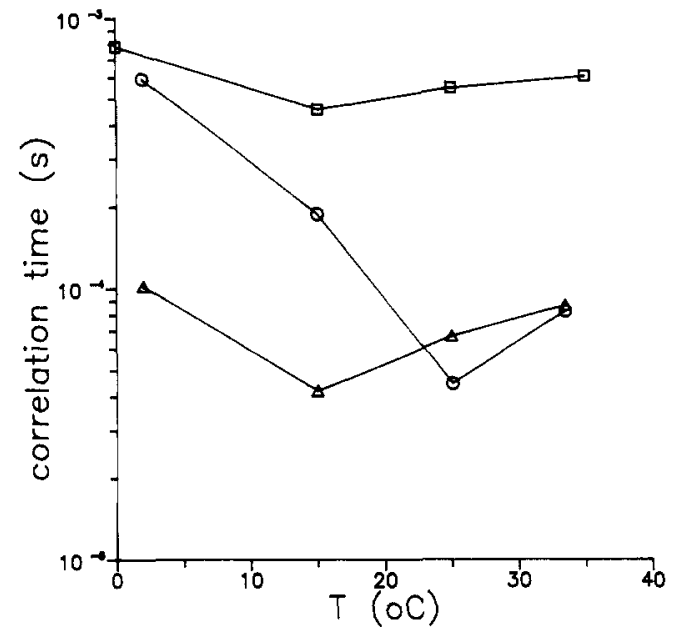

FIGURE 6: Temperature dependence of the effective rotational correlation times, deduced from the low-field line-height ratios, $L^{\prime \prime} / L$, in the second harmonic, $90^{\circ}$ out-of-phase absorption STESR spectra of covalently labeled cytochrome oxidase in complexes with cardiolipin in the absence of salt $(\Delta)$, cardiolipin in $4 \mathrm{M} \mathrm{NaCl}(\square)$, and dimyristoylphosphatidylcholine in the absence of salt $(0)$.

absence of salt are in the same region as for fluid-phase dimyristoylphosphatidylcholine. The increase in effective correlation time at high temperature in Figure 6 is probably artifactual because of overlap with the mobile component seen in the spectra of Figure 5. Nonetheless, the figure is appropriate for a qualitative comparison of the different complexes.

\section{DisCussion}

The present experiments clearly indicate that cytochrome oxidase can be reconstituted in a preparation in which nearly all the endogenous lipid [ca. $99 \%$ assuming equilibrium exchange; cf. Watts et al. (1978) and Powell et al. (1985)] is replaced by beef heart cardiolipin. The protein is uniformly distributed in the lamellar lipid vesicles as seen by freezefracture electron microscopy and undergoes rapid rotational diffusion as measured by saturation-transfer ESR spectroscopy [cf. Fajer et al. (1989)]. In the latter publication, it was concluded that the cytochrome oxidase was present most probably as a dimer in dimyristoylphosphatidylcholine above the phase transition. The similarity of the STESR spectra in Figure 5c,d suggests that this must also be the case for the cardiolipin-substituted cytochrome oxidase in the absence of salt.

Part of the lipid in the complexes reconstituted with cardiolipin can still undergo transitions to an inverted hexagonal phase, but the protein preferentially stabilizes the lamellar phase as seen by ${ }^{31}$ P NMR. As judged by electron microscopy, the inverted hexagonal lipid phase formed is devoid of protein. Similar results have been found for cardiolipin-supplemented cytochrome oxidase with respect to the $\mathrm{Ca}^{2+}$-induced inverted hexagonal-phase formation (Rietveld et al., 1987). For complexes in high salt, a certain minimal amount of cardiolipin is required for the lamellar phase of the cytochrome oxidase, as detected by ${ }^{31} \mathrm{P}$ NMR of the cardiolipin headgroups. In this phase, the protein density is very high, and the rotational mobility of the protein is reduced to levels comparable to those found in gel-phase dimyristoylphosphatidylcholine, for which electron microscopy has previously shown that cytochrome oxidase is excluded from the pure gel-phase lipid into protein-rich domains (Fajer et al., 1989).

A series of integral membrane proteins have been found to stabilize their membrane lipids against transitions to the inverted hexagonal phase. These include rhodopsin (De Grip et al., 1979; Mollevanger \& De Grip, 1984), Na,K-ATPase 
(D. Marsh and M. Esmann, unpublished results), glycophorin (Taraschi et al., 1982, 1983), and cytochrome oxidase (Rietveld et al., 1987). It may well be that $\mathrm{H}_{11}$-forming lipids are able to enhance enzymatic activity via the peculiar conformational properties of their chains, as has been illustrated for the Ca-ATPase (Navarro et al., 1984). The structure of the integral proteins, however, ensures that these lipids are maintained in their lamellar state, hence preserving the integrity of the membrane permeability barrier. In this connection, it is interesting to note that the small helical peptide gramicidin is able to induce inverted hexagonal phases (Van Echteld et al., 1981, 1982). This hydrophobic peptide does not possess the structural characteristics common to most large amphiphilic integral membrane proteins. In further contrast to the integral proteins, the extrinsic protein cytochrome $c$ has been shown to be capable of inducing nonlamellar phases in bilayers of cardiolipin (De Kruijff \& Cullis, 1980). In this respect, the behavior of cytochrome $c$ is more similar to that of ions (Seddon et al., 1983; Powell \& Marsh, 1985).

The incorporation of integral proteins into lipids capable of undergoing transitions to nonlamellar phases may have useful technological applications. From the present results for cytochrome oxidase, the $\mathrm{L}_{\alpha}-\mathrm{H}_{\text {II }}$ phase transition provides a ready means of producing lamellar lipid/protein complexes with very high protein packing densities. Variations on this method may prove helpful in attempts to form two-dimensional protein crystals. From the cell membrane standpoint, it is interesting that the nonlamellar phase formation is accompanied by a clearing of proteins from the lipid regions, since clearing has previously been suggested to be an early stage of membrane fusion in exocytosis (Satir et al., 1973; Schober et al., 1977; Volsky \& Loyter, 1978; Swift \& Mukherjee, 1978), and the fusion process itself requires the transient creation of a nonlamellar topology in the membrane lipid. The tight junction in the plasma membrane of polarized cells has also been suggested to involve a nonlamellar lipid structure (Kachar \& Reese, 1982; Pinto da Silva \& Kachar, 1982). If this were the case, then the expulsion of integral proteins from this nonlamellar region could contribute to the diffusion barrier between the apical and basolateral regions of the plasma membrane in epithelial cells (Diamond, 1977; De Kruijff et al., 1985). Although both of these cell biological aspects have more recently been questioned (Van Meer et al., 1986), they do illustrate the possibility of using this relatively simple, defined system to emulate segregation processes taking place in more complex biological systems. Finally, it has recently been suggested that the lateral segregation of membrane components may have wider functional implications (Williams, 1988).

\section{ACKNOWLEDGMENTS}

We thank D. Ashworth for carrying out the electron microscopy and Dr. S. W. Hui for helpful discussions on the interpretation of the electron micrographs and for performing supplementary freeze-fracture studies. We also thank F. Andy Norris for technical assistance.

Registry No. Dimyristoylphosphatidylcholine, 13699-48-4; cytochrome oxidase, 9001-16-5.

\section{REFERENCES}

Abramovitch, D. A., Marsh, D., \& Powell, G. L. (1990) Biochim. Biophys. Acta (submitted for publication).

Bligh, E. G., \& Dyer, W. J. (1959) Can. J. Biochem. Physiol. 37, 911-917.

Cable, M. B., \& Powell, G. L. (1980) Biochemistry 19, 5679-5686.
Cullis, P. R., \& De Kruijff, B. (1979) Biochim. Biophys. Acta 559, 399-420.

Dasgupta, U., \& Wharton, D. C. (1977) Arch. Biochem. Biophys. 183, 260-272.

De Grip, W. J., Drenthe, E. H. S., Van Echteld, C. J. A., De Kruijff, B., \& Verkleij, A. J. (1979) Biochim. Biophys. Acta 558, 330-337.

De Kruijff, B., \& Cullis, P. R. (1980) Biochim. Biophys. Acta $602,477-490$.

De Kruijff, B., Cullis, P. R., Verkleij, A. J., Hope, M. J., Van Echteld, C. J. A., Taraschi, T. F., Van Hoogevest, P., Killian, J. A., Rietveld, A., \& Van der Steen, A. T. M. (1985) in Progress in Protein-Lipid Interactions. (Watts, A., \& De Pont, J. J. H. H. M., Eds.) Vol. 1, pp 89-142, Elsevier, Amsterdam.

Diamond, J. M. (1977) Physiologist 20, 10-18.

Eibl, H., \& Lands, W. E. M. (1969) Anal. Biochem. 30, 51-57.

Fajer, P., \& Marsh, D. (1982) J. Magn. Reson. 49, 212-224.

Fajer, P., Knowles, P. F., \& Marsh, D. (1989) Biochemistry 28, 5634-5643.

Hemminga, M. A., de Jager, P. A., Marsh, D., \& Fajer, P. (1984) J. Magn. Reson. 59, 160-163.

Horvāth, L. I., \& Marsh, D. (1988) J. Magn. Reson. 80, 314-317.

Kachar, B., \& Reese, T. S. (1982) Nature 296, 464-466.

Knowles, P. F., Watts, A., \& Marsh, D. (1979) Biochemistry l8, 4480-4487.

Knowles, P. F., Watts, A., \& Marsh, D. (1981) Biochemistry 20, 5888-5894.

Lowry, O. H., Rosebrough, N. J., Farr, L., \& Randall, R. J. (1955) J. Biol. Chem. 193, 265-275.

Marsh, D., \& Powell, G. L. (1988) Bioelectrochem. Bioenerg. 20, 73-82.

Mollevanger, L. C. P. J., \& De Grip, W. J. (1984) FEBS Lett. $169,256-260$.

Navarro, J., Toivio-Kinnucan, M., \& Racker, E. (1984) Biochemistry 23, 130-135.

Pinto da Silva, P., \& Kachar, B. (1982) Cell 28, 441-450.

Powell, G. L., \& Marsh, D. (1985) Biochemistry 24, 2902-2908.

Powell, G. L., Knowles, P. F., \& Marsh, D. (1985) Biochim. Biophys. Acta 816, 191-194.

Powell, G. L., Knowles, P. F., \& Marsh, D. (1987) Biochemistry 26, 8138-8145.

Rand, R. P., \& Sengupta, S. (1972) Biochim. Biophys. Acta 255, 484-492.

Rietveld, A., Van Kemenade, T. J. J. M., Hak, T., Verkleij, A. J., \& De Kruijff, B. (1987) Eur. J. Biochem. 164, 137-140.

Robinson, N. C., Stry, F., \& Talbert, L. (1980) Biochemistry 19, 3656-3661.

Satir, B., Schooley, C., \& Satir, P. (1973) J. Cell Biol. 56, 153-176.

Schober, R., Nitsch, C., Rinne, U., \& Morris, S. J. (1977) Science 195, 495-497.

Seddon, J. M., Kaye, R. D., \& Marsh, D. (1983) Biochim. Biophys. Acta 734, 347-352.

Seelig, J. (1978) Biochim. Biophys. Acta 515, 105-140.

Swift, J. G., \& Mukherjee, T. M. (1978) J. Cell Sci. 33, 301-316.

Taraschi, T. F., De Kruijff, B., Verkleij, A. J., \& Van Echteld, C. J. A. (1982) Biochim. Biophys. Acta 685, 153-161.

Taraschi, T. F., De Kruijff, B., \& Verkleij, A. J. (1983) Eur. J. Biochem. 129, 621-625. 
Van Echteld, C. J. A., Van Stigt, R., De Kruijff, B., Leunissen-Bijvelt, J., Verkleij, A. J., \& De Gier, J. (1981) Biochim. Biophys. Acta 648, 287-291.

Van Echteld, C. J. A., De Kruijff, B., Verkleij, A. J., Leunissen-Bijvelt, J., \& De Gier, J. (1982) Biochim. Biophys. Acta 692, 126-138.

Van Meer, G., Gumbiner, B., \& Simons, K. (1986) Nature $322,639-641$
Verkleij, A. J. (1984) Biochim. Biophys. Acta 779, 43-63.

Volsky, D. J., \& Loyter, A. (1978) Biochim. Biophys. Acta 514, 213-224.

Watts, A., Marsh, D., \& Knowles, P. F. (1978) Biochim. Biophys. Acta 81, 403-409.

Williams, R. J. P. (1988) Trends Biochem. Sci. 13, 249.

Yu, C., Yu, L., \& King, T. E. (1975) J. Biol. Chem. 250, 1383-1392.

\title{
Bidirectional Transbilayer Lipid Movement in Human Platelets As Vizualized by the Fluorescent Membrane Probe 1-[4-(Trimethylammonio)phenyl]-6-phenyl-1,3,5-hexatriene ${ }^{\dagger}$
}

\author{
Edouard M. Bevers, ${ }^{*, \ddagger}$ Peter F. J. Verhallen, ${ }^{\ddagger}, 8$ Antonie J. W. G. Visser, ${ }^{\|}$Paul Comfurius, ${ }^{\ddagger}$ and Robert F. A. Zwaal ${ }^{\ddagger}$ \\ Department of Biochemistry, Research Institute for Cardiovascular Diseases, University of Limburg, P.O. Box 616, \\ 6200 MD Maastricht, The Netherlands, and Department of Biochemistry, Agricultural University, \\ Wageningen, The Netherlands \\ Received October 13, 1989; Revised Manuscript Received January 17, 1990
}

\begin{abstract}
Transbilayer movement of the fluorescent membrane probe TMA-DPH [1-[4-(trimethylammonio)phenyl]-6-phenyl-1,3,5-hexatriene] in the plasma membrane of human platelets was investigated by measuring fluorescence intensity and fluorescence decay. Labeling of unstimulated platelets by TMA-DPH results in a rapid increase in fluorescence intensity, leveling off within 1 min. Dilution of platelets into buffer without TMA-DPH leads to an almost complete rapid efflux of TMA-DPH, indicating that TMA-DPH labels only the outer leaflet of the plasma membrane. Transbilayer movement of the fluorescent probe in unstimulated platelets could be observed upon prolonged incubation and occurs with a $t_{1 / 2}$ of 60-90 min. Stimulation of platelets with thrombin directly after the initial rapid uptake of TMA-DPH results in a fast increase in membrane-bound TMA-DPH, fully explained by the increase in plasma membrane caused by secretion of intracellular storage organelles. No indications for increased transbilayer movement of the probe were found, since dilution of thrombin-stimulated TMA-DPH-labeled platelets into buffer without TMA-DPH indicated no uptake of TMA-DPH by intracellular membranes. In contrast to thrombin, stimulation of TMA-DPH-labeled platelets with the $\mathrm{Ca}^{2+}$-ionophore ionomycin results in a much larger increase in fluorescence intensity. This process is accompanied by labeling of intracellular membranes as indicated by incomplete efflux of TMA-DPH after dilution of the stimulated platelets. Thus, stimulation of platelets by ionomycin gives rise to rapid and massive inward movement of TMA-DPH $\left(t_{1 / 2} \sim 10-12\right.$ s). Prolonged incubation of platelets in the absence of any stimulus allows labeling of the total lipid pool, including intracellular membranes. Dilution experiments with these platelets showed that rapid outward movement of TMA-DPH only occurs upon stimulation with ionomycin. The high rate of transbilayer movement of TMA-DPH - both inward and outward - during stimulation by ionomycin corresponds to the randomization of phospholipids that has been described previously for platelets stimulated by $\mathrm{Ca}^{2+}$-ionophore A23187 [Bevers et al. (1983) Biochim. Biophys. Acta 736, 57-66]. These results suggest that stimulation by ionophore causes the formation of local defects (flip sites) in the plasma membrane along which both endogenous phospholipid and exogenous added lipidlike compounds can cross the bilayer in both directions. Further examination of the "flip sites" during platelet stimulation by ionomycin showed that they were only transient, disappearing within $1 \mathrm{~min}$ following addition of the stimulus.
\end{abstract}

$\mathbf{T}_{\text {he }}$ he plasma membrane of blood platelets is characterized by an asymmetrical distribution of the different phospholipid classes over both leaflets: the inner leaflet is enriched in phosphatidylethanolamine and contains virtually all the phosphatidylserine (PS) ${ }^{1}$ of the plasma membrane, whereas

\footnotetext{
${ }^{\dagger}$ This work was financially supported by The Dutch Foundation for Medical and Health Research (MEDIGON), Program Grant 900-526093.

$¥$ University of Limburg.

Present address: Schering AG, Cardiovascular Pharmacology, Laboratory for Thrombosis Research, Berlin, F.R.G.

"Agricultural University.
}

the outer monolayer is composed of a major part of the phosphatidylcholine and contains almost all the sphingomyelin (Schick et al., 1976; Chap et al., 1977; Perret et al., 1979; Bevers et al., 1983). This phospholipid distribution closely resembles that of the erythrocyte membrane (Verkley et al., 1973; Gordesky et al., 1975). In erythrocytes two different mechanisms have been considered to account for transbilayer asymmetry: translocation mediated by an ATP-dependent

\footnotetext{
${ }^{1}$ Abbreviations: PS, phosphatidylserine; TMA-DPH, 1-[4-(trimethylammonio)phenyl]-6-phenyl-1,3,5-hexatriene; $F$, fluorescence intensity; $\langle\tau\rangle$, average fluorescence lifetime.
} 